\title{
Fermented Food Consumption and Psychological Distress in Pregnant Women: A Nationwide Birth Cohort Study of the Japan Environment and Children's Study
}

\author{
Fumiaki Takahashi, ${ }^{1, *}$ Hidekazu Nishigori, ${ }^{2, *}$ Toshie Nishigori, ${ }^{2}$ Satoshi Mizuno, ${ }^{3}$ \\ Taku Obara, ${ }^{4}$ Hirohito Metoki, ${ }^{5}$ Kasumi Sakurai, ${ }^{6}$ Mami Ishikuro, ${ }^{7}$ \\ Noriyuki Iwama, ${ }^{2}$ Nozomi Tatsuta, ${ }^{8}$ Ichiko Nishijima, ${ }^{9}$ Ikuma Fujiwara, ${ }^{10}$ \\ Takahiro Arima, ${ }^{11}$ Kunihiko Nakai, ${ }^{8}$ Takashi Sugiyama, ${ }^{12}$ Shinichi Kuriyama, ${ }^{7,13}$ \\ Nobuo Yaegashi ${ }^{2}$ and the Japan Environment \& Children's Study Group

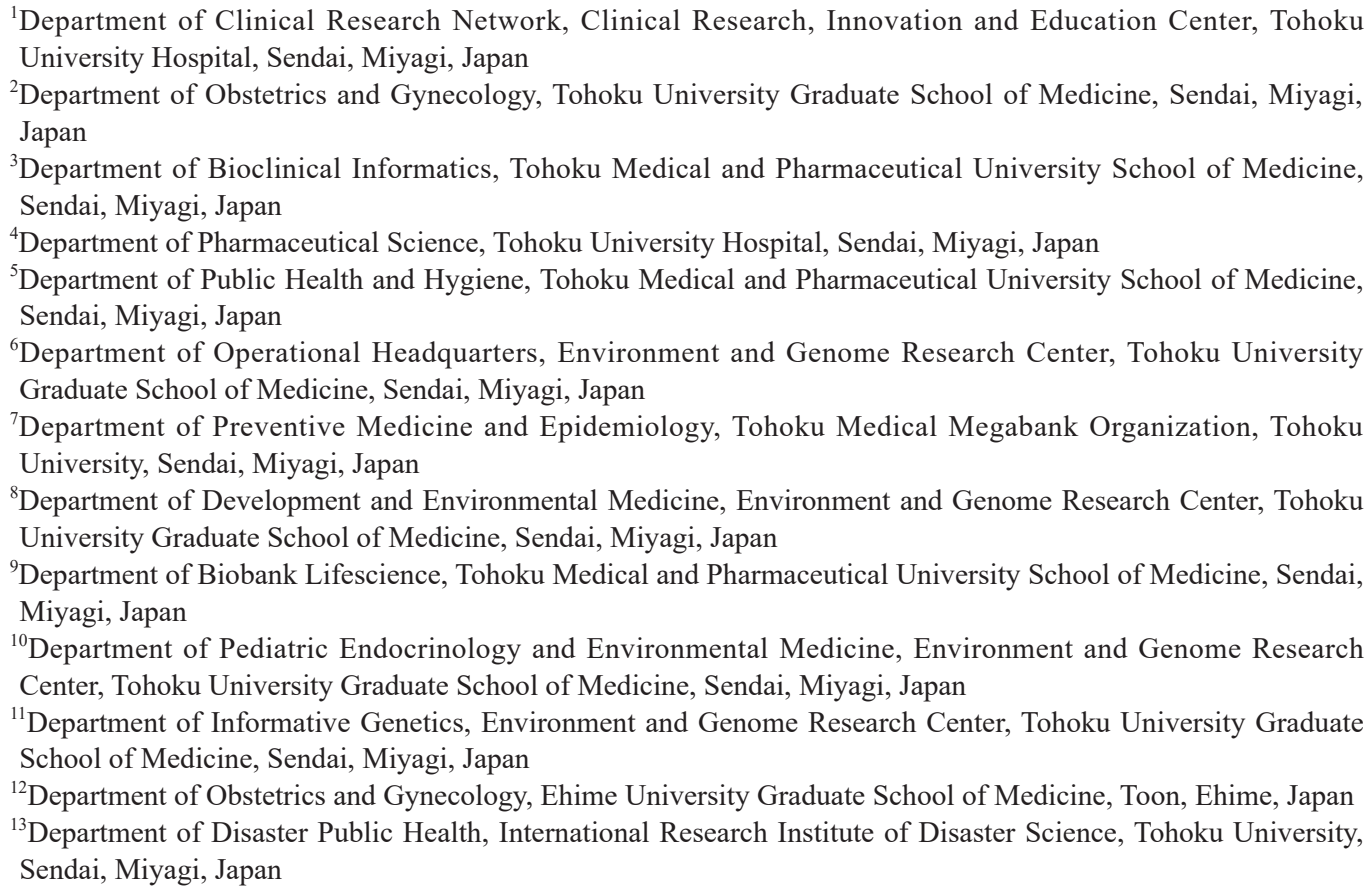

Health benefits of fermented foods are attracting attention worldwide, and they have been traditionally eaten in Japan. Moreover, a recent study showed the association between the higher intake of yogurt and lower prevalence of depressive symptoms during pregnancy. Psychological problems, such as anxiety and depression, during pregnancy are serious health concerns and may increase the risk of adverse outcomes in children. In this study, we explored the association between fermented food consumption and psychological distress in 10,129 pregnant Japanese women, using the fixed data of the Japan Environment and Children's Study (JECS), an ongoing nation-wide birth cohort study. Food consumption was assessed with a semi-quantitative food frequency questionnaire (FFQ), and the Kessler 6-item psychological distress scale (K6) was administered to eligible women during their second or third trimester to eliminate overlap with the period of hyperemesis gravidarum. The mean median gestation in the subjects was 24.8 weeks. In total, 9,030 subjects completed the K6 questionnaire and FFQ. Importantly, the prevalence of the K6 score of $\geq 13$ was $3.1 \%$ ( 280 subjects). This value was lower compared to precedent studies, which may reflect that cooperative and health conscious subject participated in the survey. The multivariate logistic regression analysis indicates that the intake of yogurt, lactic acid beverages, cheese, Japanese pickles, miso soup, or fermented soybeans was not significantly associated with a K6 score of $\geq 13$. In conclusion,

Received September 26, 2016; revised and accepted November 9, 2016. Published online December 10, 2016; doi: 10.1620/tjem.240.309.

*These authors contributed equally to this work.

Correspondence: Hidekazu Nishigori, Department of Obstetrics and Gynecology, Tohoku University Graduate School of Medicine, 1-1 Seiryo-mach, Aoba-ku, Sendai, Miyagi 980-8574, Japan.

e-mail: nishigori@med.tohoku.ac.jp 


\section{the present cohort study shows no association between fermented food consumption and psychological distress symptoms during the second or third trimester of pregnancy.}

Keywords: fermented foods; Japan Environment and Children's Study; pregnant women; psychological distress; the second or third trimester of pregnancy

Tohoku J. Exp. Med., 2016 December, 240 (4), 309-321. C 2016 Tohoku University Medical Press

\section{Introduction}

Psychological distress, such as anxiety and depression, during pregnancy are serious health concerns. Reported prevalence rates of antenatal anxiety disorders range between $6.6 \%$ and 24\% (Andersson et al. 2003; SutterDallay et al. 2004), and the prevalence rates of antenatal depression might be as high as 20\%, worldwide (Marcus et al. 2003; Bowen and Muhajarine 2006a; Faisal-Cury and Rossi Menezes 2007). Anxiety and depression during pregnancy are associated with an increased risk of preterm delivery, preeclampsia, birth difficulties, and postpartum depression (Dayan et al. 2002; Bodnar and Wisner 2005; Bowen and Muhajarine 2006b; Orr et al. 2007).

Antenatal anxiety, depression, and stress also increase the risk of a wide range of adverse outcomes in children, including emotional problems, symptoms of attention deficit hyperactivity disorder, and impaired cognitive development (Talge et al. 2007; Stein et al. 2008; Pawlby et al. 2009; Glover 2014, 2015). Children of depressed mothers also have more frequent respiratory problems and diarrhea (Stewart 2007).

Previous studies have shown an association between nutrients and depressive symptoms during pregnancy, and suggest that higher intakes of eicosapentaenoic acid, docosahexaenoic acid, and calcium are independently associated with lower prevalence of depressive symptoms in pregnant women (Miyake et al. 2013, 2015). A cross-sectional study of approximately 1,700 pregnant Japanese women found that a higher intake of yogurt was independently associated with lower prevalence of depressive symptoms during pregnancy (Miyake et al. 2015).

Recently, fermented milk products with probiotics were reported to affect activity in brain regions that control the central processing of emotion and sensation in healthy women (Tillisch et al. 2013). Animal models have also demonstrated potential signaling mechanisms, such as microbiota-produced signaling molecules and mucosal immune mechanisms, through which probiotics and gut microbiota influence brain activity (Bravo et al. 2011; McNulty et al. 2011; Neufeld et al. 2011; Cryan and Dinan 2012; Foster and McVey Neufeld 2013; Mayer et al. 2015; Mohammadi et al. 2016).

The Japanese Ministry of the Environment launched a large-scale epidemiological research project, termed The Japan Environment and Children's Study (JECS), in January 2011 (Kawamoto et al. 2014). JECS is an ongoing nationwide birth cohort study, which aims to recruit approximately 100,000 pregnant women and their partners over a period of three years, collect biological samples, and record data on their children from birth, to the age of 13 .

In the present study, we analyzed a data set from JECS, which included approximately 10,000 pregnant Japanese women, to investigate associations between psychological distress and the consumption of fermented foods such as yogurt, lactic acid beverages, cheese, Japanese pickles, miso soup, and fermented soybeans. We limited the target period of the dietary survey to the second and third trimesters to eliminate overlap with the period of hyperemesis gravidarum.

\section{Materials and Methods}

\section{Study subjects}

The JECS protocol has been published elsewhere (Kawamoto et al. 2014; Michikawa et al. 2015) and was approved by the Ministry of the Environment's Institutional Review Board on Epidemiological Studies on April 6, 2010 (no. 100406001). Informed, written consent was obtained from all participants. The present study is based on the data set jecs-ag-ai-20131008, which was released in October 2013. Registration for JECS was initiated in January 2011, on a nationwide basis, and the primary fixed data were created. This data includes 10,129 pregnant women who had given birth as of December 2011. For the JECS, participants were recruited through the 15 Regional Centers located in Hokkaido, Miyagi, Fukushima, Chiba, Kanagawa, Koshin, Toyama, Aichi, Kyoto, Osaka, Hyogo, Tottori, Kochi, Fukuoka, and South Kyushu and Okinawa (Fig. 1).

\section{Measurements}

All data was obtained from self-reported questionnaires completed by pregnant women; the "M-T2 questionnaire" for mothers during mid-late trimester pregnancy was conducted during the second or third trimester.

\section{Exposures}

Exposures in this study were the intake of probiotics, prebiotics, and other fermented foods, such as yogurt, lactic acid beverages, fermented milk, cheese, milk, Japanese pickles, miso soup (miso pastes are produced by fermenting soybeans, rice, barley, and wheat with salt and malt), fermented soybeans, and beans. Exposure was assessed with a semi-quantitative food frequency questionnaire (FFQ), which was comprised of a list of foods with standard portion sizes commonly consumed in Japan (Yokoyama et al. 2016). Participants were asked to report the daily, weekly, or monthly frequency of their consumption of a portion size of fermented foods, during the second or third trimester of pregnancy.

\section{Outcome}

The Kessler 6-item psychological distress scale (K6) is widely used as a screening tool for psychological distress in the general population (Kessler et al. 2002, 2003). It is preferred for the screening of 


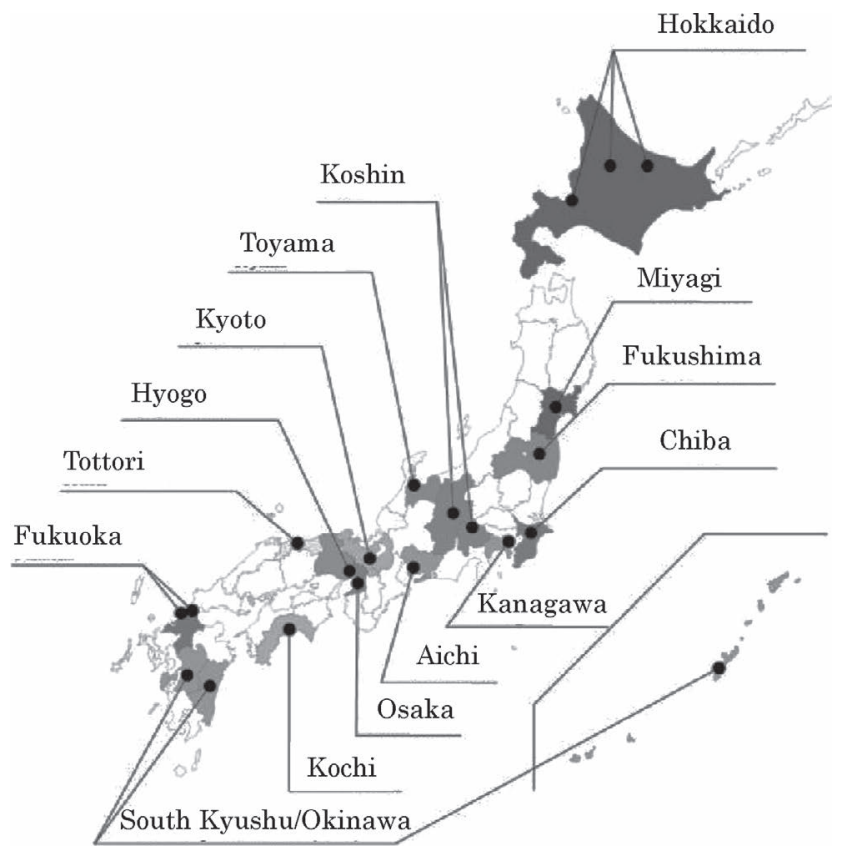

Fig. 1. Location of the 15 Regional Centers of JECS. The participants were recruited through the 15 Regional Centers of the Japan Environment and Children's Study (JECS).

DSM-IV mood or anxiety disorders, because of its brevity and consistency across subsamples. The K6 consists of six questions with five possible responses ( $0-4)$ for each question: none of the time $(0$ points), a little of the time (1 point); some of the time ( 2 points); most of the time ( 3 points); and all of the time (4 points).

The six questions are as follows: "During the past 30 days, how often have you felt the following: (1) nervous; (2) hopeless; (3) restless or fidgety; (4) so depressed that nothing would cheer you up; (5) that everything was an effort; and (6) worthless?" The total score ranges between 0 and 24. Following the suggestion of Kessler et al. (2003), we classified women with K6 scores of $\geq 13$ as having psychological distress. This cutoff point was used in previous studies that implemented the Japanese version of K6 (Hozawa et al. 2009; Watanabe et al. 2015). The Japanese version of the K6 demonstrates a screening performance essentially equal to that of the original English version (Furukawa et al. 2003, 2008).

\section{Covariates}

Information regarding parity, body mass index, marital status, family structure, number of childbirths, and mood after pregnancy was confirmed, and history of infertility treatment and mental health disorders was ascertained with a baseline questionnaire. In a followup questionnaire and the FFQ, participants also reported age, gestation, academic history, employment, household income, International Physical Activity Questionnaire short score, present smoking status, husband's present smoking status, secondhand smoking status, alcohol consumption level, total intake, drink consumption level (e.g., green tea, oolong tea, black tea, and coffee), presence of health complications or disease (e.g., hypertension, diabetes, mental health disorders, other pregnancy complications, gestational hypertension, gestational diabetes, other obstetric labor complications), intimate partner violence (IPV), and social capital (SC) during the second or third trimester of pregnancy.
The JECS questionnaire for women during the second or third trimester (the M-T2 questionnaire) includes IPV-related questions, which are answered across four response options: (1) never, (2) rarely, (3) sometimes, and (4) often. For the assessment of psychological IPV, the participants were asked, "Have you ever been insulted or reviled by your partner during the present pregnancy?" Hereafter, "during pregnancy" refers to the present pregnancy unless otherwise specified. For the assessment of physical IPV, the women were asked "Have you ever been hit or beaten by your partner due to a fight during pregnancy, resulting in injury?" To determine the incidence of IPV in the study, we considered the answers "rarely," "sometimes," and "often" to indicate the presence of psychological or physical IPV.

The M-T2 also includes SC-related questions. The following questions were answered across the five response options (1) never, (2) rarely, (3) sometimes, (4) frequently, and (5) always. Question 1: "Are there any contactable persons who show love and affection to you?" Question 2: "Are there any people who mentally support you, such as providing consultation to resolve problems and helping with difficult decision-making?" Question 3: "Do you contact persons who are familiar to you and trustworthy as frequently as you desire?" To determine the SC of the study participants, we considered the answers "sometimes," "frequently," and "always" to indicate the presence of SC.

The following SC-related question was answered across the three response options (1) none, (2) one to two, and (3) three or more: "How many relatives or friends do you have with whom you can freely consult?" To determine the SC of the study participants, we considered the answer "three or more" to indicate the presence of SC.

\section{Statistical analysis}

In this study, we used a multivariate logistic regression analysis to assess the risk of psychological distress related to fermented food consumption. Miyake et al. (2015) previously reported that a higher intake of yogurt may be associated with a lower prevalence of psychological distress in pregnant women, so here we assessed the effect of yogurt in detail. In particular, it was included as a continuous predictor in a working model, and a linear spline interpolation with one knot was used to represent a nonlinear association between food intake and the prevalence of psychological distress due to food refusal and overeating. The selection of the optimal location for the knot was based on Akaike's information criteria (Akaike 1973). All other exposures were categorized into quartile groups. All exposures and covariates that were statistically significant in the univariate analyses were included in the working multivariate logistic model.

In the main analysis, subjects with "no answer" outcomes were excluded, and incomplete covariates were categorized into a "no answer" category. To assess the robustness of our main results, we performed multiple imputation analyses with a fully conditional specification method (van Buuren 2007). Ten data sets were created, with"no answer" values replaced by imputed values based on a model that incorporated both exposure and covariates. These data sets were then combined using Rubin's rule (Rubin 1987).

The Wald test evaluated the null hypothesis that each effect in the model was 0 . The Wald test was used for evaluation of each effect in see Tables 2-7. All $\mathrm{P}$ values are two-tailed with significance set at $<0.05$ and all analyses were performed using SAS statistical software, version 9.4 (SAS Institute Inc., Cary, NC). 


\section{Results}

\section{Study subjects}

Subjects lost to follow-up during the second or third trimester of pregnancy $(n=632)$ and those with still or multiple births $(\mathrm{n}=228$ and 92 , respectively), energy intakes outside of the predefined limits $(<500 \mathrm{Kcal} /$ day or $>5,000 \mathrm{Kcal} /$ day; $\mathrm{n}=87$ ), or uncompleted $\mathrm{K} 6$ surveys $(\mathrm{n}=$ 60 ) were excluded. In total, 9,030 subjects completed the
K6 questionnaire and FFQ at M-T2 questionnaire (Fig. 2). The participants of the 15 Regional Centers and Core Center of JECS was shown in Table 1. The location of Core Center wasn't provided in the data set jecs-agai-20131008. The participants of JECS were distributed nationwide from the north, Hokkaido, to the south, Okinawa.

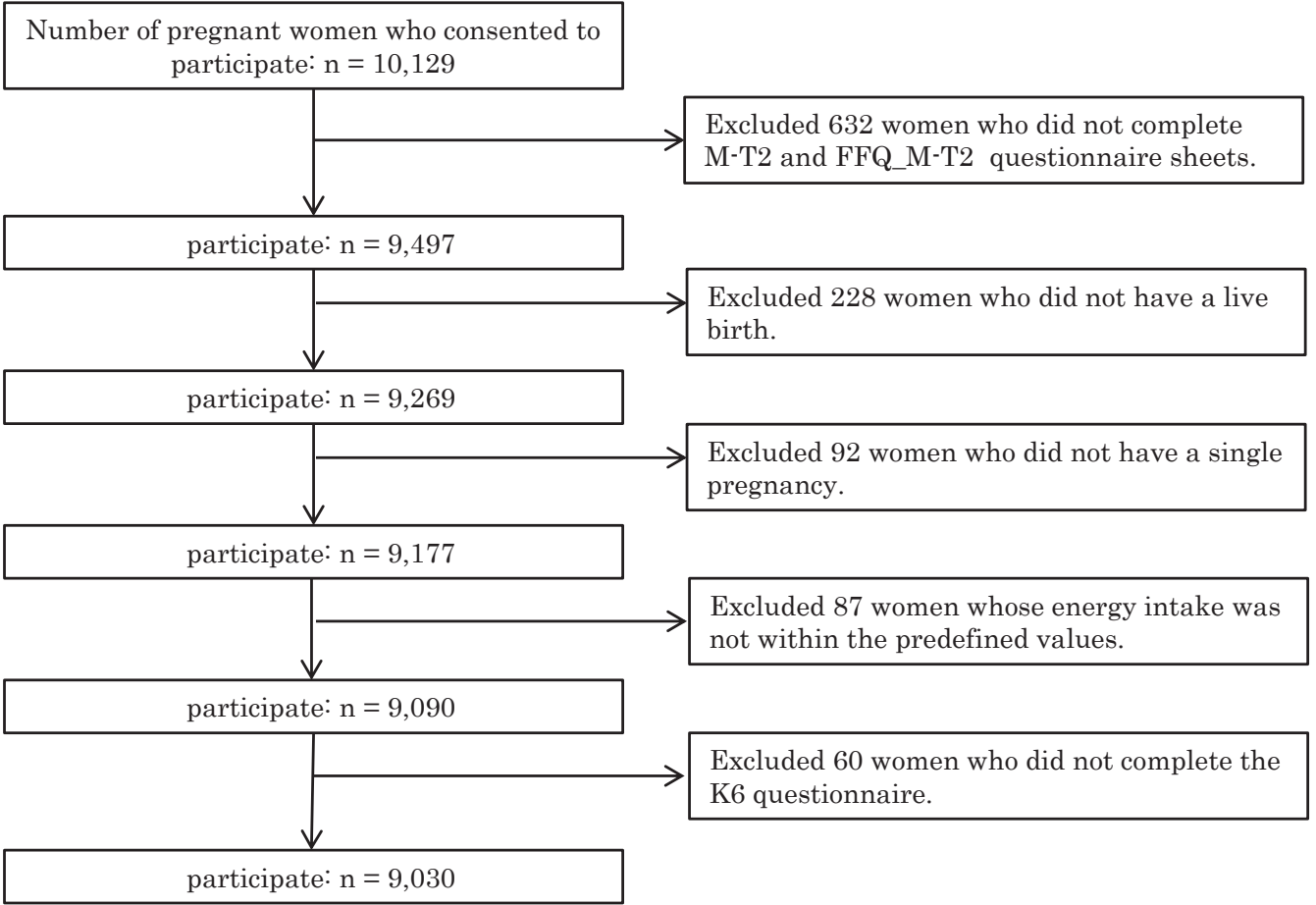

Fig. 2. Participants flow diagram.

The study analyzed 9,090 out of the 10,129 pregnant women which provided primary fixed data for the Japan Environment and Children's Study (JECS).

Questionnaire for mothers during the second or third trimester pregnancy (M-T2 questionnaire), a semi-quantitative food frequency questionnaire (FFQ), Kessler 6-item psychological distress scale (K6).

Table 1. Participants of the 15 Regional Centers and Core Center of the Japan Environment and Children's Study (Total $=9,030)$.

\begin{tabular}{lcc}
\hline \multicolumn{1}{c}{ unit center } & $\mathrm{n}$ & $\%$ \\
\hline Hokkaido & 617 & 6.8 \\
Miyagi & 1004 & 11.1 \\
Fukushima & 553 & 6.1 \\
Chiba & 469 & 5.2 \\
Kanagawa & 443 & 4.9 \\
Koshin & 783 & 8.7 \\
Toyama & 684 & 7.6 \\
Aichi & 376 & 4.2 \\
Kyoto & 141 & 1.6 \\
Osaka & 979 & 10.8 \\
Hyogo & 446 & 4.9 \\
Tottori & 291 & 3.2 \\
Kochi & 723 & 8.0 \\
Fukuoka & 811 & 9.0 \\
South Kyusyu and Okinawa & 670 & 7.4 \\
Core Center & 40 & 0.4 \\
\hline
\end{tabular}




\section{Characteristics of subjects}

Tables 2-7 showed the participant characteristics and proportion of psychological distress. The mean age and median gestation in the subjects was 31.0 years and 24.8 weeks, respectively. The prevalence of psychological distress during the second or third trimester of pregnancy was

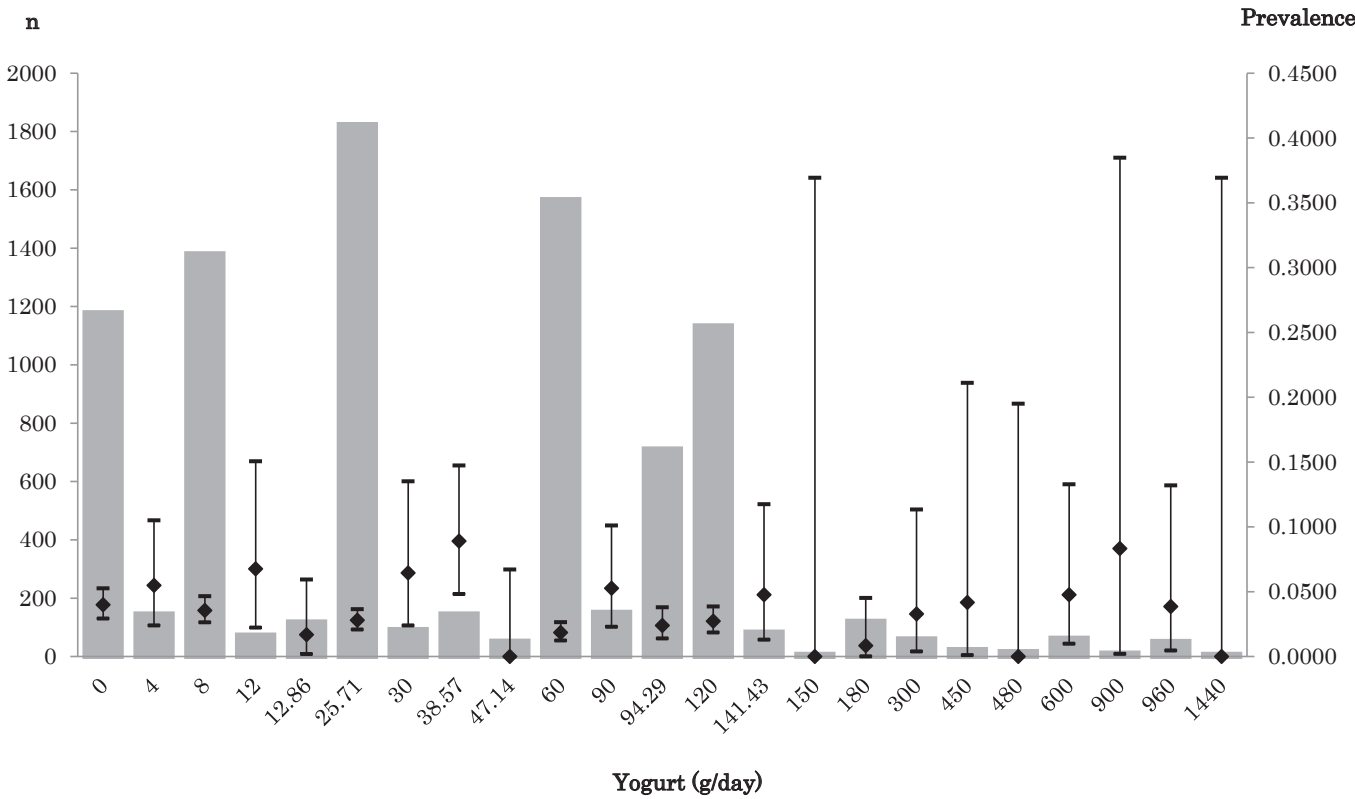

Fig. 3. Prevalence of $K 6 \geq 13$ and yogurt intake.

The mark [ ] is a prevalence of $\mathrm{K} 6 \geq 13$ and bars are $95 \%$ confidence intervals.

The histogram is a yogurt intake frequency $($ Total $=9,030)$

Table 2. Characteristics of subjects and Univariate analysis for Exposures (Fermented related foods).

\begin{tabular}{|c|c|c|c|c|c|c|c|c|c|}
\hline & & \multicolumn{2}{|c|}{$\begin{array}{c}\text { total } \\
(\mathrm{n}=9,030)\end{array}$} & \multicolumn{2}{|c|}{$\begin{array}{l}13 \leq \mathrm{K} 6 \\
(\mathrm{n}=280)\end{array}$} & \multirow[b]{2}{*}{$\mathrm{COR}$} & \multirow[b]{2}{*}{$95 \% \mathrm{CI}$} & \multirow[b]{2}{*}{$\mathrm{P}$} & \multirow[b]{2}{*}{ Wald test } \\
\hline & & $\mathrm{n}$ & $(\%)$ & $\mathrm{n}$ & $(\%)$ & & & & \\
\hline \multirow[t]{2}{*}{ Yogurt (g/day) } & $<60$ & 5015 & $(55.5)$ & 181 & $(3.6)$ & 0.991 & $0.986-0.996$ & & 0.004 \\
\hline & $\geq 60$ & 4015 & $(44.5)$ & 99 & $(2.5)$ & 1.001 & $1.000-1.002$ & & \\
\hline \multirow[t]{3}{*}{ Lactic acid beverage ( $\mathrm{ml} /$ day) } & 0 & 5445 & $(60.3)$ & 150 & $(2.8)$ & 1 & & & 0.07 \\
\hline & $<80$ & 2239 & $(24.8)$ & 81 & $(3.6)$ & 1.325 & $1.007-1.744$ & 0.04 & \\
\hline & $\geq 80$ & 1346 & $(14.9)$ & 49 & $(3.6)$ & 1.334 & $0.961-1.744$ & 0.09 & \\
\hline \multirow[t]{4}{*}{ Cheese (g/day) } & $\overline{0}$ & 1872 & $(20.7)$ & 72 & $(3.9)$ & 1 & & & 0.04 \\
\hline & $0<-\leq 2.5$ & 2689 & $(29.8)$ & 86 & $(3.2)$ & 0.826 & $0.600-1.136$ & 0.24 & \\
\hline & $2.5 \overline{<} \leq 5$ & 2352 & $(26.0)$ & 54 & $(2.3)$ & 0.587 & $0.411-0.841$ & 0.004 & \\
\hline & $>5-$ & 2117 & $(23.4)$ & 68 & $(3.2)$ & 0.830 & $0.592-1.163$ & 0.28 & \\
\hline \multirow[t]{4}{*}{ Milk (ml/day) } & 0 & 1576 & $(17.5)$ & 60 & $(3.8)$ & 1 & & & 0.09 \\
\hline & $0<-<200$ & 4696 & $(52.0)$ & 152 & $(3.2)$ & 0.845 & $0.623-1.146$ & 0.28 & \\
\hline & $200-400$ & 2065 & $(22.9)$ & 51 & $(2.5)$ & 0.640 & $0.438-0.935$ & 0.02 & \\
\hline & $>400$ & 693 & $(7.7)$ & 17 & $(2.5)$ & 0.635 & $0.368-1.097$ & 0.10 & \\
\hline \multirow[t]{4}{*}{ Japanese pickles (g/day) } & 0 & 1826 & $(20.2)$ & 63 & $(3.5)$ & 1 & & & 0.73 \\
\hline & $0<-\leq 5$ & 3296 & $(36.5)$ & 95 & $(2.9)$ & 0.831 & $0.601-1.148$ & 0.26 & \\
\hline & $5<-\leq 10$ & 1598 & $(17.7)$ & 51 & $(3.2)$ & 0.923 & $0.634-1.343$ & 0.67 & \\
\hline & $>1 \overline{0}$ & 2310 & $(25.6)$ & 71 & $(3.1)$ & 0.887 & $0.629-1.253$ & 0.50 & \\
\hline \multirow[t]{4}{*}{ Fermented soybeans } & $<1$ time/month & 1777 & $(19.7)$ & 59 & $(3.3)$ & 1 & & & 0.81 \\
\hline & 1-3 times/month & 2302 & ( 25.5$)$ & 75 & $(3.3)$ & 0.981 & $0.693-1.387$ & 0.91 & \\
\hline & 1-2 times/week & 2984 & $(33.0)$ & 86 & $(2.9)$ & 0.864 & $0.617-1.210$ & 0.40 & \\
\hline & $\geq 3$ times/week & 1967 & $(21.8)$ & 60 & $(3.1)$ & 0.916 & $0.636-1.320$ & 0.64 & \\
\hline \multirow[t]{4}{*}{ Miso soup (cup/week) } & $\leq 2$ & 2733 & $(30.3)$ & 110 & $(4.0)$ & 1 & & & 0.008 \\
\hline & $3-4$ & 1841 & $(20.4)$ & 53 & $(2.9)$ & 0.707 & $0.507-0.986$ & 0.04 & \\
\hline & $5-6$ & 2379 & $(26.3)$ & 58 & $(2.4)$ & 0.596 & $0.431-0.823$ & 0.002 & \\
\hline & $\geq 7$ & 2077 & $(23.0)$ & 59 & $(2.8)$ & 0.697 & $0.505-0.962$ & 0.03 & \\
\hline \multirow[t]{4}{*}{ Beans (g/day) } & $\leq 15$ & 1899 & $(21.0)$ & 77 & $(4.1)$ & 1 & & & 0.01 \\
\hline & $\overline{1} 5<-\leq 30$ & 2152 & $(23.8)$ & 66 & $(3.1)$ & 0.749 & $0.536-1.046$ & 0.09 & \\
\hline & $30<-\leq 60$ & 2578 & $(28.5)$ & 60 & $(2.3)$ & 0.564 & $0.400-0.794$ & 0.001 & \\
\hline & $>60^{-}$ & 2401 & $(26.6)$ & 77 & $(3.2)$ & 0.784 & $0.568-1.082$ & 0.14 & \\
\hline
\end{tabular}

The Kessler 6-item psychological distress scale (K6; total point scores ranged from 0 to 24 . We classified individuals with scores of $\geq 13 / 24$ as having psychological distress.), COR (crude odds ratio), CI (confidence interval), The Wald test evaluates the null hypothesis that each effect in the model is 0 (Wald test). 
Table 3. Characteristics of subjects and Univariate analysis for Covariates (Information from the baseline questionnaire; Social, Lifestyle, and Pregnancy-related items).

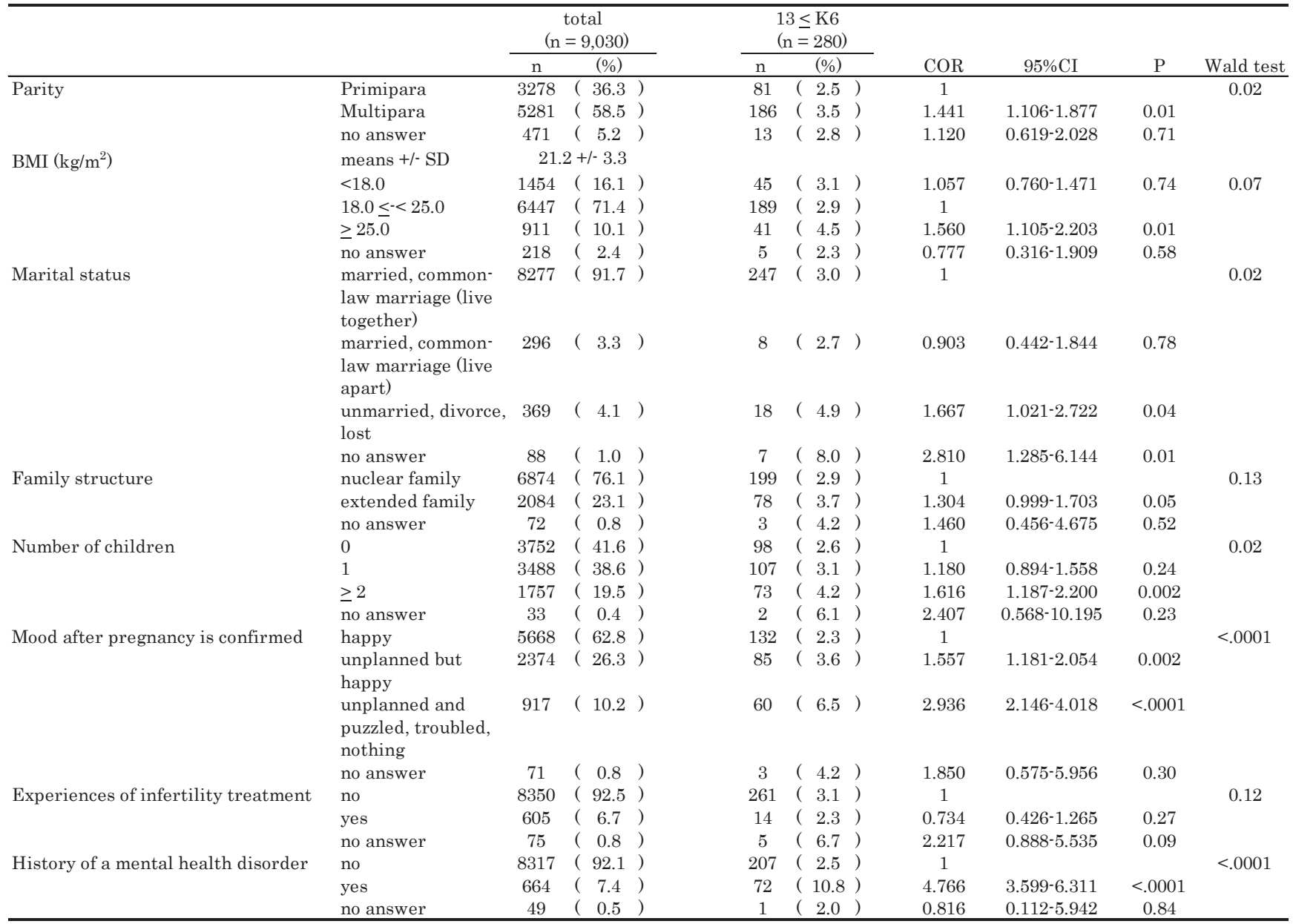

BMI (body mass index), SD (standard deviation).

\section{$3.1 \%$ (280 subjects).}

\section{Prevalence of psychological distress and intake of yogurt}

Fig. 3 showed a histogram that indicates the prevalence of psychological distress and its $95 \%$ confidence interval (CI). The median intake of yogurt was $25.71 \mathrm{~g} /$ day, which corresponds to approximately 1 cup of yogurt (120 g) consumed by a Japanese woman once or twice per week. We fit a linear spline model with one knot to this data, and the estimate of the optimal knot for yogurt intake was $60 \mathrm{~g} /$ day.

\section{Univariate analysis for fermented related foods}

Lower yogurt intake was significantly associated with a lower prevalence of psychological distress (crude odds ratio [COR]: 0.991; 95\% CI: 0.986-0.996; $\mathrm{P}=0.0009$ ) within the range of 0 to $60 \mathrm{~g} /$ day. However, at $60 \mathrm{~g} /$ day or more, higher yogurt intake was not associated with lower prevalence (COR: 1.001; 95\% CI: 1.000-1.002; P = 0.20). Associations between psychological distress and the intake of cheese, miso soup, and beans were investigated using a univariate analysis. Higher intakes of these foods tended to be associated with lower prevalence of psychological distress. The univariate analysis showed no associations between psychological distress, and the intake of lactic acid beverages, milk, Japanese pickles, or fermented soybeans (Table 2).

\section{Multivariate regression analysis for fermented related foods}

Associated covariates were parity, body mass index, marital status, number of children, mood after pregnancy, history of mental health disorders, age, academic history, job type, household income, International Physical Activity Questionnaire short score, present smoking status, husband's present smoking status, secondhand smoking status, total intake, intake of black tea, mental health disorder, other obstetric labor complications, IPV, and SC. In multivariate logistic regression model included these covariates, "the adjusted effects" of yogurt, cheese, miso soup, and beans were not significantly associated with the prevalence of psychological distress during the second or third trimester of pregnancy (Table 8). Notably, the results obtained with the multiple imputation method corroborated those of the main analysis. In healthy pregnant women without 
Table 4. Characteristics of subjects and Univariate analysis for Covariates (Information from the follow-up questionnaire; Social, Lifestyle, and Pregnancy-related items).

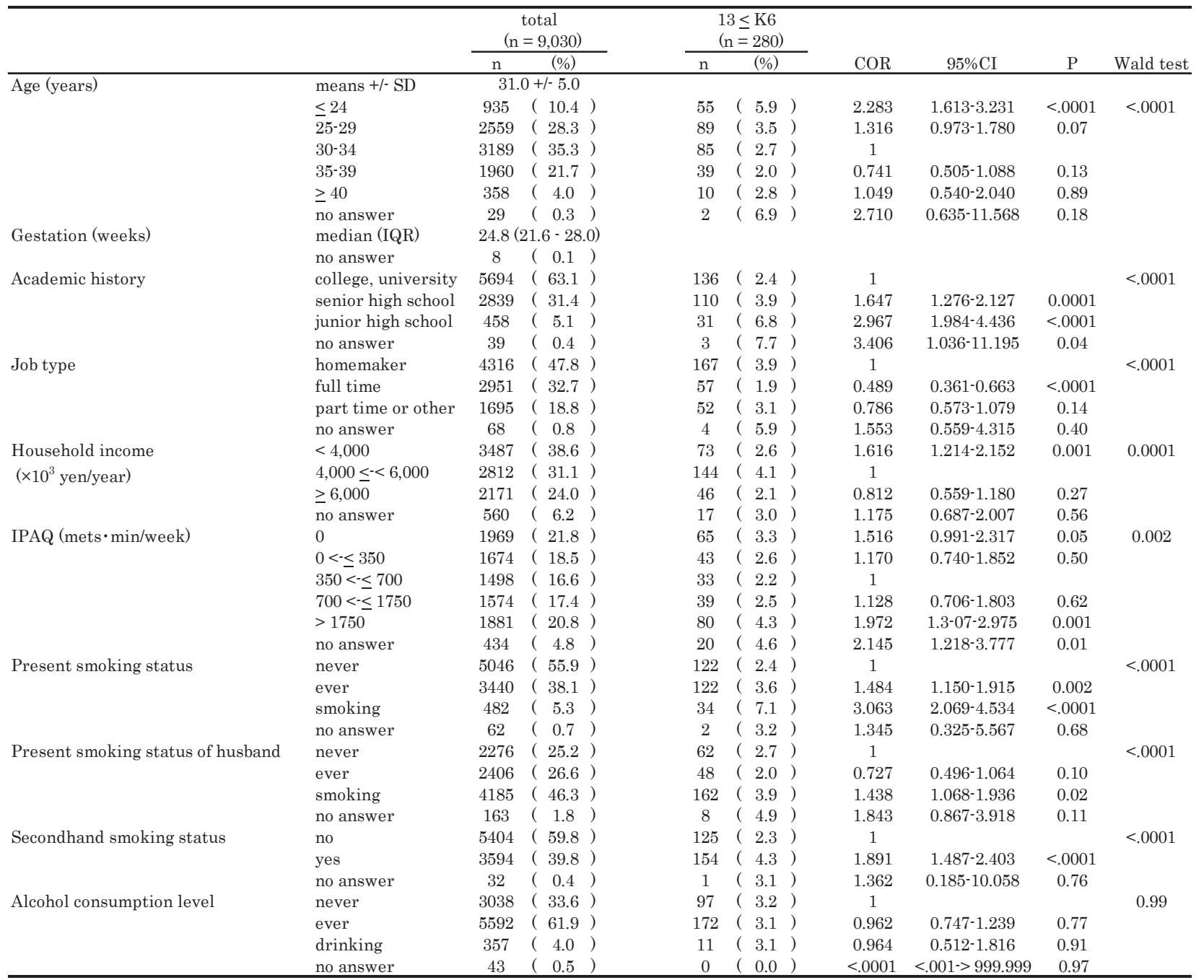

IQR (interquartile range), IPAQ (the International Physical Activity Questionnaire) short scoring.

Table 5. Characteristics of subjects and Univariate analysis for Covariates (Information from the follow-up questionnaire; Total energy and Drink consumption).

\begin{tabular}{|c|c|c|c|c|c|c|c|c|c|}
\hline & & \multicolumn{2}{|c|}{$\begin{array}{c}\text { total } \\
(\mathrm{n}=9,030)\end{array}$} & \multicolumn{2}{|c|}{$\begin{array}{l}13 \leq \mathrm{K} 6 \\
(\mathrm{n}=280)\end{array}$} & \multirow[b]{2}{*}{ COR } & \multirow[b]{2}{*}{$95 \% \mathrm{CI}$} & \multirow[b]{2}{*}{$\mathrm{P}$} & \multirow[b]{2}{*}{ Wald test } \\
\hline & & $\mathrm{n}$ & $(\%)$ & $\mathrm{n}$ & $(\%)$ & & & & \\
\hline \multirow[t]{5}{*}{ Total energy (kcal/day) } & means $+/-\mathrm{SD}$ & 1725 & $0+/-606.6$ & & & & & & \\
\hline & $500 \leq-<1200$ & 1482 & $(16.4)$ & 51 & $(3.4)$ & 1.327 & $0.912-1.930$ & 0.14 & 0.005 \\
\hline & $1200 \leq-<1600$ & 2849 & $(31.6)$ & 72 & $(2.5)$ & 0.965 & $0.685-1.359$ & 0.84 & \\
\hline & $1600 \leq-\leq 2000$ & 2408 & $(26.7)$ & 63 & $(2.6)$ & 1 & & & \\
\hline & $2000<-\leq 5000$ & 2291 & $(25.4)$ & 94 & $(4.1)$ & 1.593 & $1.151-2.203$ & 0.005 & \\
\hline \multirow[t]{3}{*}{ Green tea (cup/day)* } & 0 & 3347 & $(37.1)$ & 102 & $(3.1)$ & 1 & & & 0.76 \\
\hline & $1-2$ & 1162 & $(12.9)$ & 37 & $(3.2)$ & 1.046 & $0.714-1.533$ & 0.82 & \\
\hline & $>2$ & 1419 & $(15.7)$ & 50 & $(3.5)$ & 1.162 & $0.824-1.639$ & 0.39 & \\
\hline \multirow[t]{4}{*}{ Oolong tea (cup/day)* } & 0 & 5751 & $(63.7)$ & 157 & $(2.7)$ & 1 & & & 0.051 \\
\hline & $<1$ & 2317 & $(25.7)$ & 89 & $(3.8)$ & 1.424 & $1.093-1.855$ & 0.01 & \\
\hline & $1-2$ & 462 & $\left(\begin{array}{ll}5.1\end{array}\right)$ & 18 & $(3.9)$ & 1.445 & $0.879-2.376$ & 0.15 & \\
\hline & $>2$ & 500 & $(5.5)$ & 16 & $(3.2)$ & 1.178 & $0.698-1.986$ & 0.54 & \\
\hline \multirow[t]{2}{*}{ Black tea (cup/day)* } & 0 & 5390 & $(59.7)$ & 147 & $(2.7)$ & 1 & & & 0.01 \\
\hline & $<1$ & 3139 & $(34.8)$ & 107 & $(3.4)$ & 1.259 & $0.977-1.621$ & 0.07 & \\
\hline \multirow{3}{*}{ Coffee (cup/day)* } & $<1$ & 2779 & $(30.8)$ & 70 & $(2.5)$ & 0.708 & $0.530-0.945$ & 0.02 & \\
\hline & $1-2$ & 1359 & $(15.0)$ & 38 & $(2.8)$ & 0.788 & $0.549-1.132$ & 0.20 & \\
\hline & $>2$ & 746 & $(8.3)$ & 26 & $(3.5)$ & 0.989 & $0.647-1.513$ & 0.96 & \\
\hline
\end{tabular}

*A cup of tea is approximately $120 \mathrm{~mL}$. 
Table 6. Characteristics of subjects and Univariate analysis for Covariates (Information from the follow-up questionnaire; Occurrence of complications or disease).

\begin{tabular}{|c|c|c|c|c|c|c|c|c|c|}
\hline & & \multicolumn{2}{|c|}{$\begin{array}{c}\text { total } \\
(\mathrm{n}=9,030)\end{array}$} & \multicolumn{2}{|c|}{$\begin{array}{l}13 \leq \mathrm{K} 6 \\
(\mathrm{n}=280)\end{array}$} & \multirow[b]{2}{*}{$\mathrm{COR}$} & \multirow[b]{2}{*}{$95 \% \mathrm{CI}$} & \multirow[b]{2}{*}{$\mathrm{P}$} & \multirow[b]{2}{*}{ Wald test } \\
\hline & & $\mathrm{n}$ & $(\%)$ & $\mathrm{n}$ & $(\%)$ & & & & \\
\hline \multirow[t]{2}{*}{ Hypertension } & no & 8879 & $(98.3)$ & 272 & $(3.1)$ & 1 & & & 0.12 \\
\hline & yes & 151 & $(1.7)$ & 8 & $(5.3)$ & 1.770 & $0.860-3.645$ & 0.12 & \\
\hline \multirow[t]{2}{*}{ Diabetes } & no & 8903 & $(98.6)$ & 277 & $(3.1)$ & 1 & & & 0.63 \\
\hline & yes & 127 & $(1.4)$ & 3 & $(2.4)$ & 0.754 & $0.238-2.383$ & 0.63 & \\
\hline \multirow[t]{2}{*}{ Mental health disorder } & no & 8957 & $(99.2)$ & 271 & $(3.0)$ & 1 & & & $<.0001$ \\
\hline & yes & 73 & $(0.8)$ & 9 & $(12.3)$ & 4.507 & $2.220-9.151$ & $<.0001$ & \\
\hline \multirow[t]{2}{*}{ Other pregnancy complication } & no & 8087 & ( 89.6$)$ & 252 & $(3.1)$ & 1 & & & 0.81 \\
\hline & yes & 943 & $(10.4)$ & 28 & $(3.0)$ & 0.951 & $0.640-1.414$ & 0.81 & \\
\hline \multirow[t]{3}{*}{ Hypertensive disorders of pregnancy } & no & 8751 & $(96.9)$ & 270 & $(3.1)$ & 1 & & & 0.78 \\
\hline & mild & 187 & $\left(\begin{array}{ll}2.1\end{array}\right)$ & 6 & $(3.2)$ & 1.041 & $0.458-2.370$ & 0.92 & \\
\hline & severe & 92 & $(1.0)$ & 4 & $4.4)$ & 1.428 & $0.520-3.917$ & 0.49 & \\
\hline \multirow[t]{2}{*}{ Gestational diabetes } & no & 8819 & $(97.7)$ & 273 & $(3.1)$ & 1 & & & 0.85 \\
\hline & yes & 211 & $(2.3)$ & 7 & $3.3)$ & 1.074 & $0.501-2.304$ & 0.85 & \\
\hline \multirow[t]{2}{*}{ Other obstetric labor complication } & no & 5263 & $(58.3)$ & 143 & $(2.7)$ & 1 & & & 0.01 \\
\hline & yes & 3767 & $(41.7)$ & 137 & $(3.6)$ & 1.351 & $1.065-1.715$ & 0.01 & \\
\hline
\end{tabular}

Table 7. Characteristics of subjects and Univariate analysis for Covariates (Information from the follow-up questionnaire; Intimate partner violence and Social capital).

\begin{tabular}{|c|c|c|c|c|c|c|c|c|c|}
\hline & & \multicolumn{2}{|c|}{$\begin{array}{c}\text { total } \\
(\mathrm{n}=9,030)\end{array}$} & \multicolumn{2}{|c|}{$\begin{array}{l}13 \leq \mathrm{K} 6 \\
(\mathrm{n}=280)\end{array}$} & \multirow[b]{2}{*}{ COR } & \multirow[b]{2}{*}{$95 \% \mathrm{CI}$} & \multirow[b]{2}{*}{$\mathrm{P}$} & \multirow[b]{2}{*}{ Wald test } \\
\hline & & $\mathrm{n}$ & $(\%)$ & $\mathrm{n}$ & $(\%)$ & & & & \\
\hline \multicolumn{10}{|l|}{ Intimate partner violence (IPV) } \\
\hline \multirow{3}{*}{$\begin{array}{l}\text { Have you ever been insulted or reviled by your } \\
\text { partner during the present pregnancy? }\end{array}$} & no & 7856 & $(87.0)$ & 183 & $2.3)$ & 1 & & & $<.0001$ \\
\hline & yes & 1097 & $(12.1)$ & 94 & $8.6)$ & 3.930 & $3.038-5.083$ & $<.0001$ & \\
\hline & no answer & 77 & $\left(\begin{array}{ll}0.9\end{array}\right)$ & 3 & $3.9)$ & 1.700 & $0.531-5.442$ & 0.37 & \\
\hline \multirow{3}{*}{$\begin{array}{l}\text { Have you ever been hit or beaten by your partner } \\
\text { due to a fight during pregnancy, resulting in } \\
\text { injury? }\end{array}$} & no & 8776 & $(97.2)$ & 250 & $2.9)$ & 1 & & & $<.0001$ \\
\hline & yes & 194 & $(2.1)$ & 29 & $(15.0)$ & 5.995 & $3.962-9.071$ & $<.0001$ & \\
\hline & no answer & 60 & $\left(\begin{array}{ll}0.7\end{array}\right)$ & 1 & $(1.7)$ & 0.578 & $0.080-4.189$ & 0.59 & \\
\hline \multicolumn{10}{|l|}{ Social caital $(S C)$} \\
\hline \multirow{3}{*}{$\begin{array}{l}\text { Are there any contactable people who show love } \\
\text { and affection to you? }\end{array}$} & yes & 7898 & $(87.5)$ & 207 & $(2.6)$ & 1 & & & $<.0001$ \\
\hline & no & 1035 & $(11.5)$ & 72 & $(7.0)$ & 2.778 & $2.107-3.662$ & $<.0001$ & \\
\hline & no answer & 97 & $(1.1)$ & 1 & $(1.0)$ & 0.387 & $0.054-2.789$ & 0.35 & \\
\hline \multirow{3}{*}{$\begin{array}{l}\text { Are there any people who mentally support you, } \\
\text { such as providing consultation to resolve problems } \\
\text { and helping with difficult decision-making? }\end{array}$} & yes & 8131 & $(90.0)$ & 210 & $(2.6)$ & 1 & & & $<.0001$ \\
\hline & no & 866 & $(9.6)$ & 68 & $(7.9)$ & 3.214 & $2.422-4.266$ & $<.0001$ & \\
\hline & no answer & 33 & $(0.4)$ & 2 & $(6.1)$ & 2.433 & $0.579-10.235$ & 0.23 & \\
\hline \multirow{3}{*}{$\begin{array}{l}\text { Do you contact persons who are familiar to you and } \\
\text { trustworthy as frequently as you desire? }\end{array}$} & yes & 7667 & $(84.9)$ & 190 & $(2.5)$ & 1 & & & $<.0001$ \\
\hline & no & 1327 & $(14.7)$ & 90 & $(6.8)$ & 2.863 & $2.212-3.706$ & $<.0001$ & \\
\hline & no answer & 36 & $(0.4)$ & 0 & $(0.0)$ & $<.0001$ & $<.001->999.999$ & 0.98 & \\
\hline \multirow{3}{*}{$\begin{array}{l}\text { How many relatives or friends do you have with } \\
\text { whom you can freely consult do you have? }\end{array}$} & $\geq 3$ & 5495 & $(60.9)$ & 107 & $(2.0)$ & 1 & & & $<.0001$ \\
\hline & $\overline{0}-2$ & 3518 & $(39.0)$ & 173 & $(4.9)$ & 2.604 & 2.039-3.327 & $<.0001$ & \\
\hline & no answer & 17 & $(0.2)$ & 0 & $(0.0)$ & $<.001$ & $<.001->999.999$ & 0.98 & \\
\hline
\end{tabular}

mental health disorders (9,030 subjects), "the adjusted effects" of yogurt, cheese, miso soup, and beans were not significantly associated with the prevalence of psychological distress during the second or third trimester of pregnancy (data not shown).

\section{Discussion}

The present cohort study demonstrated that the consumption of yogurt and other fermented foods is not associated with lower prevalence of a K6 score of $\geq 13$ in pregnant women. This finding differed from our expectations, based on previous research by Miyake et al. (2015), who reported that a higher intake of yogurt was associated with lower prevalence of depressive symptoms during pregnancy. The difference between our results and those reported by Miyake et al. (2015) may be attributable to several factors. The study by Miyake et al. (2015) used the Japanese version of the Center for Epidemiologic Studies Depression Scale (Radloff 1977; Shima et al. 1985) to measure the presence of depressive symptoms. Miyake et al. (2015) also recruited participants from Fukuoka City and Okinawa Prefecture on Kyushu, in Japan. Furthermore, data collected during the first trimester, a period corresponding to the peak occurrence of hyperemesis gravidarum (Lacroix et al. 2000), were included in their study, and approximately $34 \%$ of the study population was evaluated during this period. Finally, in their study, subjects were categorized into quartile groups, and the prevalence of depressive symptoms among groups was evaluated. By contrast, our study used the Japanese version of $\mathrm{K} 6$, which is the 
Table 8. Multivariate regression analysis for fermented related foods $($ Total $=9,030)$.

\begin{tabular}{|c|c|c|c|c|}
\hline & & $\mathrm{AOR}^{*}$ & $95 \% \mathrm{CI}$ & $\mathrm{P}$ \\
\hline \multicolumn{5}{|l|}{ Exposures } \\
\hline \multirow[t]{2}{*}{$\overline{\text { Yogurt (g/day) }}$} & $<60$ & 0.997 & $0.992-1.003$ & 0.41 \\
\hline & $\geq 60$ & 1.001 & 0.999-1.002 & 0.36 \\
\hline \multirow[t]{4}{*}{ Cheese (g/day) } & $\overline{0}$ & 1 & & \\
\hline & $0<-\leq 2.5$ & 0.948 & $0.674-1.334$ & 0.76 \\
\hline & $2.5<-\leq 5$ & 0.706 & $0.477-1.047$ & 0.08 \\
\hline & $>5-$ & 0.989 & $0.668-1.465$ & 0.96 \\
\hline \multirow[t]{4}{*}{ Miso soup (cup/week) } & $\leq 2$ & 1 & & \\
\hline & $\overline{3}-4$ & 0.817 & $0.574-1.163$ & 0.26 \\
\hline & $5-6$ & 0.743 & $0.526-1.049$ & 0.09 \\
\hline & $\geq 7$ & 0.771 & $0.542-1.097$ & 0.15 \\
\hline \multirow[t]{4}{*}{ Beans (g/day) } & $\overline{\leq} 15$ & 1 & & \\
\hline & $\overline{1} 5<-\leq 30$ & 0.953 & $0.662-1.372$ & 0.80 \\
\hline & $30<-\leq 60$ & 0.714 & $0.485-1.049$ & 0.09 \\
\hline & $>60^{-}$ & 0.934 & $0.637-1.370$ & 0.73 \\
\hline \multicolumn{5}{|c|}{ Covariates } \\
\hline \multicolumn{5}{|c|}{ Information from the baseline questionnaire } \\
\hline \multirow[t]{3}{*}{ Parity } & Primipara & 1 & & \\
\hline & Multipara & 1.407 & $0.660-3.001$ & 0.38 \\
\hline & no answer & 1.123 & $0.594-2.121$ & 0.72 \\
\hline \multirow[t]{4}{*}{ BMI $\left(\mathrm{kg} / \mathrm{m}^{2}\right)$} & $<18.0$ & 0.975 & $0.687-1.384$ & 0.89 \\
\hline & $18.0-25.0$ & 1 & & \\
\hline & $\geq 25.0$ & 1.263 & $0.868-1.837$ & 0.22 \\
\hline & $\overline{\text { no answer }}$ & 0.630 & $0.239-1.662$ & 0.35 \\
\hline \multirow[t]{4}{*}{ Marital status } & $\begin{array}{l}\text { married, common-law } \\
\text { marriage (live together) }\end{array}$ & 1 & & \\
\hline & $\begin{array}{l}\text { married, common-law } \\
\text { marriage (live apart) }\end{array}$ & 0.700 & $0.328-1.496$ & 0.36 \\
\hline & unmarried, divorce, lost & 0.978 & $0.553-1.731$ & 0.94 \\
\hline & no answer & 3.688 & $1.336-10.179$ & 0.01 \\
\hline \multirow[t]{4}{*}{ Number of children } & 0 & 1 & & \\
\hline & 1 & 0.887 & $0.424-1.854$ & 0.75 \\
\hline & $\geq 2$ & 1.013 & $0.476-2.155$ & 0.97 \\
\hline & $\overline{\text { no answer }}$ & 8.578 & $0.834-88.263$ & 0.07 \\
\hline \multirow[t]{4}{*}{ Mood after pregnancy is confirmed } & happy & 1 & & \\
\hline & unplanned but happy & 1.100 & $0.814-1.488$ & 0.54 \\
\hline & $\begin{array}{l}\text { unplanned and puzzled, } \\
\text { troubled, nothing }\end{array}$ & 1.794 & $1.249-2.576$ & 0.002 \\
\hline & no answer & 2.688 & $0.400-18.075$ & 0.31 \\
\hline \multirow[t]{3}{*}{ History of a mental disorder } & no & 1 & & \\
\hline & yes & 3.773 & 2.729-5.215 & $<.0001$ \\
\hline & no answer & $>999.999$ & $<.0001->999.999$ & 0.99 \\
\hline
\end{tabular}

AOR (adjusted odds ratio), CI (confidence interval).

*Adjusted for all the items listed in Table 8, Table 8 (continued-1), and Table 8 (continued-2).

preferred survey for DSM-IV mood or anxiety disorder screening, and we recruited Japanese participants nationwide. Furthermore, we limited the target period of the dietary survey to the second and third trimesters, to eliminate overlap with the period of hyperemesis gravidarum. Finally, the study subjects in our analysis were not categorized.

Nausea and vomiting during pregnancy are reported by $75 \%$ of pregnant women and last an average of 35 days. Half of these women experienced relief of these symptoms by 14 weeks, and $90 \%$ do so by 22 weeks (Lacroix et al. 2000). The subjects of the study by Miyake et al. (2015) could not deny the influence of nausea and vomiting on their answers to a comprehensive diet history questionnaire, administered to assess dietary habits during the first trimester of pregnancy. With this in mind, our study used the M-T2 questionnaire to avoid the influence of nausea and vomiting during pregnancy on questionnaire responses, for more accurate accounting of daily food intake.

The findings of the present study may also conflict with expectations based on previous research by Tillisch et al. (2013). The discrepancies between our findings are likely due to the fact that Tillisch et al. (2013) limited their evaluation to fermented milk products and yogurt produced 
Table 8. $($ continued-1) $($ Total $=9,030)$.

\begin{tabular}{|c|c|c|c|c|}
\hline & & AOR* & $95 \% \mathrm{CI}$ & $\mathrm{P}$ \\
\hline \multicolumn{5}{|c|}{ Information from the follow-up questionnaire } \\
\hline \multirow[t]{6}{*}{ Age (years) } & $\leq 24$ & 1.980 & $1.308-2.997$ & 0.001 \\
\hline & $\overline{2} 5-29$ & 1.313 & $0.948-1.817$ & 0.10 \\
\hline & $30-34$ & 1 & & \\
\hline & 35-39 & 0.657 & $0.437-0.989$ & 0.04 \\
\hline & $\geq 40$ & 0.860 & $0.429-1.724$ & 0.67 \\
\hline & no answer & 3.490 & $0.743-16.392$ & 0.11 \\
\hline \multirow[t]{4}{*}{ Academic history } & college, university & 1 & & \\
\hline & senior high school & 0.895 & $0.665-1.205$ & 0.47 \\
\hline & junior high school & 0.688 & $0.412-1.148$ & 0.15 \\
\hline & no answer & 1.352 & $0.331-5.528$ & 0.67 \\
\hline \multirow[t]{4}{*}{ Job type } & no & 1 & & \\
\hline & yes (full time) & 0.558 & $0.394-0.789$ & 0.001 \\
\hline & yes (part time) & 0.656 & $0.465-0.926$ & 0.02 \\
\hline & no answer & 1.274 & $0.399-4.072$ & 0.68 \\
\hline \multirow[t]{4}{*}{ Household income ( $10^{3}$ yen/year) } & $<4,000$ & 1.016 & $0.742-1.391$ & 0.92 \\
\hline & $4,000 \leq-<6,000$ & 1 & & \\
\hline & $\geq 6,000$ & 1.062 & $0.714-1.580$ & 0.77 \\
\hline & no answer & 0.930 & $0.517-1.671$ & 0.81 \\
\hline \multirow[t]{6}{*}{ IPAQ (mets· min/week) } & 0 & 1.535 & $0.980-2.404$ & 0.06 \\
\hline & $0<-\leq 350$ & 1.188 & $0.739-1.911$ & 0.48 \\
\hline & $350 \overline{<}-\leq 700$ & 1 & & \\
\hline & $700<-\leq 1750$ & 1.107 & $0.680-1.801$ & 0.68 \\
\hline & $>1750$ & 1.712 & $1.103-2.658$ & 0.02 \\
\hline & no answer & 1.958 & $1.064-3.601$ & 0.03 \\
\hline \multirow[t]{4}{*}{ Present smoking status } & never & 1 & & \\
\hline & ever & 1.082 & $0.813-1.438$ & 0.59 \\
\hline & smoking & 1.088 & $0.668-1.772$ & 0.73 \\
\hline & no answer & 0.567 & $0.121-2.654$ & 0.47 \\
\hline \multirow[t]{4}{*}{ Present smoking status of husband } & never & 1 & & \\
\hline & ever & 0.670 & 0.449-0.999 & 0.0496 \\
\hline & smoking & 0.932 & $0.661-1.316$ & 0.69 \\
\hline & no answer & 0.912 & $0.379-2.196$ & 0.84 \\
\hline \multirow[t]{3}{*}{ Secondhand smoking status } & no & 1 & & \\
\hline & yes & 1.191 & $0.894-1.585$ & 0.23 \\
\hline & no answer & 1.527 & $0.192-12.150$ & 0.69 \\
\hline
\end{tabular}

using five Lactobacillus strains and our study population was restricted to pregnant women. Different yogurt products contain different strains of lactobacillus and may have differential effects (Bravo et al. 2011; McNulty et al. 2011; Neufeld et al. 2011; Cryan and Dinan 2012; Mohammadi et al. 2016), which could explain the discrepancy in the results. The trade names of the fermented milk and yogurt products consumed by our study participants were not recorded in our survey.

The prevalence of psychological distress during the second or third trimester of pregnancy was $3.1 \%$. This value was lower than precedent studies (Marcus et al. 2003; Andersson et al. 2003; Sutter-Dallay et al. 2004; Bowen and Muhajarine 2006a; Faisal-Cury and Rossi Menezes 2007). The subjects of this survey were limited to only pregnant women that participated in JECS voluntarily. Thus, a number of cooperative and health conscious pregnant women likely participated in the survey. Therefore, there was some selection bias here.
The limitations of our study include the non-uniformity of food products and brands, the wide variation in bacterial species and strains among the consumed products, even within those of the same type, and the potential inhomogeneity of the study population due to regional variations in dietary culture.

In conclusion, we show no association between psychological distress during the second and third trimester of pregnancy, and the consumption of yogurt, lactic acid beverages, cheese, fermented milk, Japanese pickles, miso soup, fermented soybeans, or beans. However, in light of the study limitations, further studies are needed to confirm our findings.

\section{Acknowledgments}

Members of the Japan Environment and Children's Study (JECS) as of 2015 (principal investigator, Toshihiro Kawamoto): Hirohisa Saito (National Center for Child Health and Development, Tokyo, Japan), Reiko Kishi (Hokkaido University, 
Table 8. $($ continued-2) $($ Total $=9,030)$.

\begin{tabular}{|c|c|c|c|c|}
\hline & & $\mathrm{AOR}^{*}$ & $95 \% \mathrm{CI}$ & $\mathrm{P}$ \\
\hline \multirow[t]{4}{*}{ Total energy (kcal/day) } & $500 \leq-<1200$ & 1.050 & $0.692-1.595$ & 0.82 \\
\hline & $1200 \leq-<1600$ & 0.925 & $0.643-1.330$ & 0.67 \\
\hline & $1600 \leq-\leq 2000$ & 1 & & \\
\hline & $2000<-\leq 5000$ & 1.592 & $1.119-2.264$ & 0.01 \\
\hline \multirow[t]{3}{*}{ Black tea (cup/day)** } & 0 & 1 & & \\
\hline & $<1$ & 1.193 & $0.909-1.566$ & 0.20 \\
\hline & $\geq 1$ & 1.486 & $0.932-2.369$ & 0.10 \\
\hline \multicolumn{5}{|l|}{ Occurrence of complications or disease } \\
\hline \multirow[t]{2}{*}{ Mental health disorder } & no & 1 & & \\
\hline & yes & 1.244 & $0.539-2.871$ & 0.61 \\
\hline \multirow[t]{2}{*}{ Other obstetric labor complication } & no & 1 & & \\
\hline & yes & 1.341 & $1.040-1.728$ & 0.02 \\
\hline \multicolumn{5}{|l|}{ Intimate partner violence (IPV) } \\
\hline \multirow{3}{*}{$\begin{array}{l}\text { Have you ever been insulted or reviled by your partner } \\
\text { during the present pregnancy? }\end{array}$} & no & 1 & & \\
\hline & yes & 2.243 & $1.646-3.057$ & $<.0001$ \\
\hline & no answer & 5.745 & $0.945-34.923$ & 0.06 \\
\hline \multirow{3}{*}{$\begin{array}{l}\text { Have you ever been hit or beaten by your partner due to } \\
\text { a fight during pregnancy, resulting in injury? }\end{array}$} & no & 1 & & \\
\hline & yes & 1.876 & $1.132-3.107$ & 0.01 \\
\hline & no answer & $<.001$ & $<.001->999.999$ & 0.99 \\
\hline \multicolumn{5}{|l|}{ Social Capital (SC) } \\
\hline \multirow{3}{*}{$\begin{array}{l}\text { Are there any contactable people who show love and } \\
\text { affection to you? }\end{array}$} & yes & 1 & & \\
\hline & no & 1.214 & $0.822-1.769$ & 0.31 \\
\hline & no answer & 0.161 & $0.017-1.487$ & 0.11 \\
\hline \multirow{3}{*}{$\begin{array}{l}\text { Are there any people who mentally support you, such as } \\
\text { providing consultation to resolve problems and helping } \\
\text { with difficult decision-making? }\end{array}$} & yes & 1 & & \\
\hline & no & 1.275 & $0.855-1.902$ & 0.23 \\
\hline & no answer & 8.308 & $1.427-48.364$ & 0.02 \\
\hline \multirow{3}{*}{$\begin{array}{l}\text { Do you contact persons who are familiar to you and } \\
\text { trustworthy as frequently as you desire? }\end{array}$} & yes & 1 & & \\
\hline & no & 1.516 & 1.094-2.102 & 0.01 \\
\hline & no answer & $<.001$ & $<.001->999.999$ & 0.98 \\
\hline \multirow{3}{*}{$\begin{array}{l}\text { How many relatives or friends do you have with whom } \\
\text { you can freely consult do you have? }\end{array}$} & $\geq 3$ & 1 & & \\
\hline & $\overline{0}-2$ & 1.814 & $1.380-2.384$ & $<.0001$ \\
\hline & no answer & $<.001$ & $<.001->999.999$ & 0.99 \\
\hline
\end{tabular}

**A cup of tea is approximately $120 \mathrm{~mL}$.

Sapporo, Japan), Nobuo Yaegashi (Tohoku University, Sendai, Japan), Koichi Hashimoto (Fukushima Medical University, Fukushima, Japan), Chisato Mori (Chiba University, Chiba, Japan), Fumiki Hirahara (Yokohama City University, Yokohama, Japan), Zentaro Yamagata (University of Yamanashi, Chuo, Japan), Hidekuni Inadera (University of Toyama, Toyama, Japan), Michihiro Kamijima (Nagoya City University, Nagoya, Japan), Ikuo Konishi (Kyoto University, Kyoto, Japan), Hiroyasu Iso (Osaka University, Suita, Japan), Masayuki Shima (Hyogo College of Medicine, Nishinomiya, Japan), Toshihide Ogawa (Tottori University, Yonago, Japan), Narufumi Suganuma (Kochi University, Nankoku, Japan), Koichi Kusuhara (University of Occupational and Environmental Health, Kitakyushu, Japan), Takahiko Katoh (Kumamoto University, Kumamoto, Japan).

\section{Funding}

The Japan Environment and Children's Study was funded by the Ministry of the Environment, Japan. The findings and conclusions of this article are solely the responsibility of the authors and do not represent the official views of the above government. This research was also supported by Research Promotion and Practical Use for Women's Health, AMED.

\section{Conflict of Interest}

The authors declare no conflict of interest.

\section{References}

Akaike, H. (1973) Information theory and an extension of the maximum likelihood principle. In Proceedings of The 2nd International Symposium on Information Theory, edited by Petrov, B.N. \& Csaki, F. Budapest, pp. 268-281.

Andersson, L., Sundström-Poromaa, I., Bixo, M., Wulff, M., Bondestam, K. \& AStröm, M. (2003) Point prevalence of psychiatric disorders during the second trimester of pregnancy: a population-based study. Am. J. Obstet. Gynecol., 189, 148-154.

Bodnar, L.M. \& Wisner, K.L. (2005) Nutrition and depression: implications for improving mental health among childbearingaged women. Biol. Psychiatry, 58, 679-685.

Bowen, A. \& Muhajarine, N. (2006a) Prevalence of antenatal depression in women enrolled in an outreach program in Canada. J. Obstet. Gynecol. Neonatal Nurs., 35, 491-498.

Bowen, A. \& Muhajarine, N. (2006b) Antenatal depression. Can. Nurse, 102, 26-30.

Bravo, J.A., Forsythe, P., Chew, M.V., Escaravage, E., Savignac, H.M., Dinan, T.G., Bienenstock, J. \& Cryan, J.F. (2011) 
Ingestion of Lactobacillus strain regulates emotional behavior and central GABA receptor expression in a mouse via the vagus nerve. Proc. Natl. Acad. Sci. USA, 108, 16050-16055.

Cryan, J.F. \& Dinan, T.G. (2012) Mind-altering microorganisms: the impact of the gut microbiota on brain and behaviour. Nat. Rev. Neurosci., 13, 701-712.

Dayan, J., Creveuil, C., Herlicoviez, M., Herbel, C., Baranger, E., Savoye, C. \& Thouin, A. (2002) Role of anxiety and depression in the onset of spontaneous preterm labor. Am. J. Epidemiol., 155, 293-301.

Faisal-Cury, A. \& Rossi Menezes, P. (2007) Prevalence of anxiety and depression during pregnancy in a private setting sample. Arch. Womens Ment. Health, 10, 25-32.

Foster, J.A. \& McVey Neufeld, K.A. (2013) Gut-brain axis: how the microbiome influences anxiety and depression. Trends Neurosci., 36, 305-312.

Furukawa, T.A., Kawakami, N., Saitoh, M., Ono, Y., Nakane, Y., Nakamura, Y., Tachimori, H., Iwata, N., Uda, H., Nakane, H., Watanabe, M., Naganuma, Y., Hata, Y., Kobayashi, M., Miyake, Y., et al. (2008) The performance of the Japanese version of the K6 and K10 in the World Mental Health Survey Japan. Int. J. Methods Psychiatr. Res., 17, 152-158.

Furukawa, T.A., Kessler, R.C., Slade, T. \& Andrews, G. (2003) The performance of the K6 and K10 screening scales for psychological distress in the Australian National Survey of Mental Health and Well-Being. Psychol. Med., 33, 357-362.

Glover, V. (2014) Maternal depression, anxiety and stress during pregnancy and child outcome; what needs to be done. Best Pract. Res. Clin. Obstet. Gynaecol., 28, 25-35.

Glover, V. (2015) Prenatal stress and its effects on the fetus and the child: possible underlying biological mechanisms. Adv. Neurobiol., 10, 269-283.

Hozawa, A., Kuriyama, S., Nakaya, N., Ohmori-Matsuda, K., Kakizaki, M., Sone, T., Nagai, M., Sugawara, Y., Nitta, A., Tomata, Y., Niu, K. \& Tsuji, I. (2009) Green tea consumption is associated with lower psychological distress in a general population: the Ohsaki Cohort 2006 Study. Am. J. Clin. Nutr., 90, 1390-1396.

Kawamoto, T., Nitta, H., Murata, K., Toda, E., Tsukamoto, N., Hasegawa, M., Yamagata, Z., Kayama, F., Kishi, R., Ohya, Y., Saito, H., Sago, H., Okuyama, M., Ogata, T., Yokoya, S., et al. (2014) Rationale and study design of the Japan environment and children's study (JECS). BMC Public Health, 14, 25.

Kessler, R.C., Andrews, G., Colpe, L.J., Hiripi, E., Mroczek, D.K., Normand, S.L., Walters, E.E. \& Zaslavsky, A.M. (2002) Short screening scales to monitor population prevalences and trends in non-specific psychological distress. Psychol. Med., 32, 959-976.

Kessler, R.C., Barker, P.R., Colpe, L.J., Epstein, J.F., Gfroerer, J.C., Hiripi, E., Howes, M.J., Normand, S.L., Manderscheid, R.W., Walters, E.E. \& Zaslavsky, A.M. (2003) Screening for serious mental illness in the general population. Arch. Gen. Psychiatry, 60, 184-189.

Lacroix, R., Eason, E. \& Melzack, R. (2000) Nausea and vomiting during pregnancy: a prospective study of its frequency, intensity, and pattern of change. Am. J. Obstet. Gynecol., 182, 931-937.

Marcus, S.M., Flynn, H.A., Blow, F.C. \& Barry, K.L. (2003) Depressive symptoms among pregnant women screened in obstetrics settings. J. Womens Health (Larchmt), 12, 373-380.

Mayer, E.A., Tillisch, K. \& Gupta, A. (2015) Gut/brain axis and the microbiota. J. Clin. Invest., 125, 926-938.

McNulty, N.P., Yatsunenko, T., Hsiao, A., Faith, J.J., Muegge, B.D., Goodman, A.L., Henrissat, B., Oozeer, R., Cools-Portier, S., Gobert, G., Chervaux, C., Knights, D., Lozupone, C.A., Knight, R., Duncan, A.E., et al. (2011) The impact of a consortium of fermented milk strains on the gut microbiome of gnotobiotic mice and monozygotic twins. Sci. Transl. Med., 3, 106 ra106.
Michikawa, T., Nitta, H., Nakayama, S.F., Ono, M., Yonemoto, J., Tamura, K., Suda, E., Ito, H., Takeuchi, A. \& Kawamoto, T.; Japan Environment and Children's Study Group (2015) The Japan Environment and Children's Study (JECS): a preliminary report on selected characteristics of approximately 10000 pregnant women recruited during the first year of the study. J. Epidemiol., 25, 452-458.

Miyake, Y., Tanaka, K., Okubo, H., Sasaki, S. \& Arakawa, M. (2013) Fish and fat intake and prevalence of depressive symptoms during pregnancy in Japan: baseline data from the Kyushu Okinawa Maternal and Child Health Study. $J$. Psychiatr. Res., 47, 572-578.

Miyake, Y., Tanaka, K., Okubo, H., Sasaki, S. \& Arakawa, M. (2015) Intake of dairy products and calcium and prevalence of depressive symptoms during pregnancy in Japan: a crosssectional study. BJOG, 122, 336-343.

Mohammadi, A.A., Jazayeri, S., Khosravi-Darani, K., Solati, Z., Mohammadpour, N., Asemi, Z., Adab, Z., Djalali, M., TehraniDoost, M., Hosseini, M. \& Eghtesadi, S. (2016) The effects of probiotics on mental health and hypothalamic-pituitaryadrenal axis: a randomized, double-blind, placebo-controlled trial in petrochemical workers. Nutr. Neurosci., 19, 387-395

Neufeld, K.M., Kang, N., Bienenstock, J. \& Foster, J.A. (2011) Reduced anxiety-like behavior and central neurochemical change in germ-free mice. Neurogastroenterol. Motil., 23, 255-264.

Orr, S.T., Reiter, J.P., Blazer, D.G. \& James, S.A. (2007) Maternal prenatal pregnancy-related anxiety and spontaneous preterm birth in Baltimore, Maryland. Psychosom. Med., 69, 566-750.

Pawlby, S., Hay, D.F., Sharp, D., Waters, C.S. \& O'Keane, V. (2009) Antenatal depression predicts depression in adolescent offspring: prospective longitudinal community-based study. $J$. Affect. Disord., 113, 236-243.

Radloff, L.S. (1977) The CES-D scale. A self-report depression scale for research in the general population. Appl. Psychol. Meas., 1, 385-401.

Rubin, D.B. (1987) Multiple Imputation for Nonresponse in Surveys, Wiley Publishing, Canada.

Shima, S., Shikano, T., Kitamura, T. \& Asai, M. (1985) New selfrated scale for depression. Jpn. J. Clin. Psychiatry, 27, 717-723 (in Japanese).

Stein, A., Malmberg, L.E., Sylva, K., Barnes, J. \& Leach, P.; FCCC team (2008) The influence of maternal depression, caregiving, and socioeconomic status in the post-natal year on children's language development. Child Care Health Dev., 34, 603-612.

Stewart, R.C. (2007) Maternal depression and infant growth: a review of recent evidence. Matern. Child Nutr., 3, 94-107.

Sutter-Dallay, A.L., Giaconne-Marcesche, V., Glatigny-Dallay, E. \& Verdoux, H. (2004) Women with anxiety disorders during pregnancy are at increased risk of intense postnatal depressive symptoms: a prospective survey of the MATQUID cohort. Eur. Psychiatry, 19, 459-463.

Talge, N.M., Neal, C. \& Glover, V.; Early Stress, Translational Research and Prevention Science Network; Fetal and Neonatal Experience on Child and Adolescent Mental Health (2007) Antenatal maternal stress and long-term effects on child neurodevelopment: how and why? J. Child Psychol. Psychiatry, 48, 245-261.

Tillisch, K., Labus, J., Kilpatrick, L., Jiang, Z., Stains, J., Ebrat, B., Guyonnet, D., Legrain-Raspaud, S., Trotin, B., Naliboff, B. \& Mayer, E.A. (2013) Consumption of fermented milk product with probiotic modulates brain activity. Gastroenterology, 144, 1394-1401.

van Buuren, S. (2007) Multiple imputation of discrete and continuous data by fully conditional specification. Stat. Methods Med. Res., 16, 219-242.

Watanabe, Z., Iwama, N., Nishigori, H., Nishigori, T., Mizuno, S., Sakurai, K., Ishikuro, M., Obara, T., Tatsuta, N., Nishijima, I., Fujiwara, I., Nakai, K., Arima, T., Takeda, T., Sugawara, J., et 
al. (2015) Psychological distress during pregnancy in Miyagi after the Great East Japan Earthquake: the Japan Environment and Children's Study. J. Affect. Disord., 190, 341-348.

Yokoyama, Y., Takachi, R., Ishihara, J., Ishii, Y., Sasazuki, S., Sawada, N., Shinozawa, Y., Tanaka, J., Kato, E., Kitamura, K., Nakamura, K. \& Tsugane, S. (2016) Validity of Short and
Long Self-Administered Food Frequency Questionnaires in Ranking Dietary Intake in Middle-Aged and Elderly Japanese in the Japan Public Health Center-Based Prospective Study for the Next Generation (JPHC-NEXT) Protocol Area. J. Epidemiol., 26, 420-432. 